University of Denver

Digital Commons @ DU

$11-1-2014$

\title{
Statistical Scheduling of Economic Dispatch and Energy Reserves of Hybrid Power Systems with High Renewable Energy Penetration
}

Yi Gu

University of Denver

Follow this and additional works at: https://digitalcommons.du.edu/etd

Part of the Electrical and Computer Engineering Commons

\section{Recommended Citation}

$\mathrm{Gu}, \mathrm{Yi}$, "Statistical Scheduling of Economic Dispatch and Energy Reserves of Hybrid Power Systems with High Renewable Energy Penetration" (2014). Electronic Theses and Dissertations. 258.

https://digitalcommons.du.edu/etd/258

This Thesis is brought to you for free and open access by the Graduate Studies at Digital Commons @ DU. It has been accepted for inclusion in Electronic Theses and Dissertations by an authorized administrator of Digital Commons@DU.For more information, please contact jennifer.cox@du.edu,dig-commons@du.edu. 
Statistical Scheduling of Economic Dispatch And Energy

Reserves of Hybrid Power Systems with High Renewable

ENERgy PENETRATion

\begin{abstract}
A THESIS
PRESENTED TO

the Faculty of the Daniel Felix Ritchie School of Engineering And Computer Science

University OF DENVER
\end{abstract}

in Partial Fulfillment

of the Requirements for the Degree

of Master of Science

YI GU

November, 2014

Advisor: Jun Zhang 
(c) Copyright by Yi Gu, 2014.

All Rights Reserved 
Author: Yi Gu

Title: Statistical Scheduling of Economic Dispatch and Energy Reserves of Hybrid Power Systems with High Renewable Energy Penetration

Advisor: Jun Zhang

Degree Date: November, 2014

\section{Abstract}

A statistical scheduling approach to economic dispatch and energy reserves is proposed in this paper. The proposed approach focuses on minimizing the overall power operating cost with considerations of renewable energy uncertainty and power system security. A hybrid power system generates electricity from both conventional and renewable energy sources. In such a system, it is challenging and yet an open question on the scheduling of economic dispatch together with energy reserves, due to renewable energy generation uncertainty, and spatially wide distribution of energy resources. The hybrid power system scheduling is formulated as a convex programming problem to minimize power operating cost, taking considerations of renewable energy generation, power generation-consumption balance and power system security. This new approach for scheduling hybrid power economic dispatch and energy reserves will contribute to the emerging grand challenge of renewable energy integration into the existing power system facilities.

A genetic algorithm based approach is used for solving the minimization of the power operating cost. The IEEE 24-bus reliability test system (IEEE-RTS), which is commonly used for evaluating the price stability of power system and reliability, is used as the test bench for verifying and evaluating system performance of the proposed scheduling approach. 


\section{Contents}

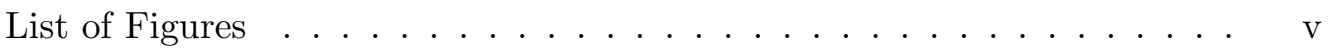

1 Introduction 1

1.1 Motivation and background . . . . . . . . . . . . . 1

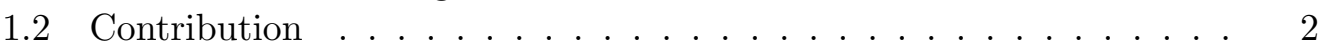

1.3 Thesis outline . . . . . . . . . . . . . . . 3

2 Literature review $\quad 4$

3 Joint statistical scheduling of economic dispatch and energy re$\begin{array}{lr}\text { serves } & 9\end{array}$

3.1 Wind turbine modelling . . . . . . . . . . . . . . . 9

3.1.1 Wind turbine characteristics ............. 9

3.1.2 Statistical wind power generation modelling . . . . . . . . . . 10

3.2 Formulation of Joint Economic Dispatch and Energy Reserves . . . . 11

3.3 Derivation and transformation of chance constraint . . . . . . . . . . 14

3.4 Genetic algorithm . . . . . . . . . . . . . . . . . . 17

3.4 Methodology of GA . . . . . . . . . . . . 18

3.4.2 Genetic algorithm application . . . . . . . . . . . . 19

3.4.3 Other information . . . . . . . . . . . . . 20

4 Numerical results $\quad 21$

4.1 Results on a typical energy scheduling scenario . . . . . . . . . . . . 22

4.2 Results on different wind energy penetrations ratios . . . . . . . . 25

4.3 Results on different chance constraint probability . . . . . . . . . 26

4.4 The scheduling of economic dispatch and reserve energy on contingency problems ..................... 27

4.5 Monte Carlo simulation . . . . . . . . . . . . . . 30

5 Conclusion and future work $\quad 34$

5.1 Conclusion . . . . . . . . . . . . . . . . . . 34

5.2 Future work . . . . . . . . . . . . . . . . . 35

5.2.1 Improvement of stochastic model with wind power . . . . . 35

5.2 .2 Improvement of the proposed method . . . . . . . . . . 36 


\section{List of Figures}

3.1 IEEE 24-bus RTS. . . . . . . . . . . . . . . . . . 11

3.2 Gaussian distribution. . . . . . . . . . . . . . . . 13

4.1 The total power operating cost of TG, WTG and RV. . . . . . . 22

4.2 The total output power of TG, WTG and RV, respectively. . . . . . 22

4.3 The average output power of TG, WTG and RV, respectively. . . . 23

4.4 The average price of TG, WTG, RV and PR, respectively. . . . . . 23

4.5 The output power of each TG, respectively. . . . . . . . . . . 23

4.6 The output power of each WTG, respectively. . . . . . . . . . . . 24

4.7 The output power of each RV, respectively. . . . . . . . . . . 24

4.8 The total power operating costs of different wind energy penetrations. 26

4.9 The total power operating cost with different chance constraints. . . 27

4.10 The emergency events of the system with sudden changes in load. . . 28

4.11 The total power operating cost at each minute. . . . . . . . . . 28

4.12 The total output power of TG, WTG and RV, respectively. . . . . . 29

4.13 The average output power of TG, WTG and RV, respectively. . . . . 29 
4.14 The average price of TG, WTG, RV and PR, respectively. . . . . . . 30

4.15 The output power of each TG, respectively. . . . . . . . . . . . . 31

4.16 The output power of each WTG, respectively. . . . . . . . . . . . 31

4.17 The output power of each RV, respectively. . . . . . . . . . . . . . 32

4.18 The Monte Carlo simulation test bench in Power World. . . . . . . . 33 


\section{Chapter 1}

\section{Introduction}

\subsection{Motivation and background}

The optimal scheduling of economic dispatch and energy reserves in a hybrid power system becomes a new challenge in renewable energy integration (REI) re-

cently. The scheduling objective is minimizing the power operating cost in a hybrid power system with high renewable energy penetration. A credible scheduling economic dispatch and energy reserves is able to increase the efficiency of the power production and ensure the reliability of the power system operations. The population around world is predicted to double by 2050 [15], and the energy demand would be certainly keep growing. As what has happened, the energy demand rised and the prices of some energy resources increased over last two or three decades. To enhance the energy demand rising and avoid environment pollution increasing simultaneously, one solution is to use much more renewable energy from wind, solar and others. In [33], the wind power capacity is expected to increase to 48,000 MW by 2020 which is threefold to the amount in 2004 .

Recently, contingency reserve scheduling with high renewable energy penetration in hybrid power systems rises as a new challenge. In [33], the new challenge is 
proposed as a key issue in power system operations on how much the most the wind power can be used to replace the fossil energy with limited wind forecasting ability synchronously. In this thesis, a new power system with a hybrid power market is constructed to study the trade-off between the system reliability and energy operating cost. Some problems are created by the new structured power system consequently, because the price and the reliability are correlated. It is hard to avoid the price increasing with the demand of high reliability of the system, and the high price will cause the residential and industrial customers complaining. According to [10], a new hybrid power system with renewable energy is recommended to deal with the present status. A reliability and price model considering the corresponding between each other with different generation suppliers is proposed here. The author gives the result with the new technique in a new environment, which illustrates that the proposed model with the new technique can reduce the operating cost efficiently and keeping the system reliability.

\subsection{Contribution}

The objective of this thesis is to propose a novel approach, which is able to schedule a hybrid power system containing conventional and renewable energy generation while ensuring power system reliability. Contributions of this work are listed below:

1. Propose an objective function for economic dispatch and energy reserve scheduling built based on the electricity generation cost and power system reliability, considering stochastic characteristics of renewable energy.

2. Developed reliability constraints from a probability format into a feasible convex format in order to solve the nonlinear stochastic problem. Considering the complexity of the optimization problem, a revised genetic algorithm is used. 
3. The IEEE 24-bus reliability testing system (RTS) is analysed and built in power world as the test bench in our study, which contains 10 generators, 24 buses, 5 transformers, 38 transmission lines and 17 loads. 4 wind plants are used to substitute 4 conventional generators in the original RTS model. Each wind turbine generator in the wind plants is defined to serve both the spot market and the reserve market.

4. The proposed approach is demonstrated in the IEEE 24-bus Reliability Testing System with Monte Carlo simulation.

\subsection{Thesis outline}

Chapter 2 reviews the present state-of-the-art of economic dispatch and energy reserve with renewable energy, with emphasis on their optimization in hybrid power systems. Chapter 3 introduces the proposed statistical economic dispatch and energy research approaches, including system objective function, wind power modelling, chance constraint and genetic algorithm. Chapter 4 illustrates and explains the numerical results on validating and evaluating the proposed approach. Chapter 5 concludes the work presented in the thesis, and discusses potential future work. 


\section{Chapter 2}

\section{Literature review}

As renewable energy penetration keeps increasing in modern power systems, new wind plants are having an increasingly prominent contribution on renewable energy penetration [9], [29], scheduling such hybrid power systems becomes an emerging challenge and urgent requirement on the road map of renewable energy integration.

In [26], a general framework is proposed on how to determine the amount of spinning reserve with large wind power penetration, however, this method is based on [36] which does not evaluate the impacts of wind generation uncertainty, and concentrates on conventional energy generator outage and load forecast errors. An approach of managing stochastic renewable energy generation uncertainty is considered in [30], and the approach generates schedules for a 24-hour period with hourly resolution. In [41], a stochastic optimal power scheduling of generators and reserves with large wind generation is studied on the WSCC-179 buses testing model [3]. A probabilistic method is proposed in [12] to optimize the spinning reserve on different level of loads, which is caused by the generator outages or the load forecast errors. In [25], a novel approach is used to determine the optimal reserve with wind penetration in a power system. The technique focuses on researching the conventional generation outages and load forecasting errors of the system, which shows a larger 
spinning reserve is not necessarily required if the wind penetration increasing during the operating process.

In [36], the operating reserve is considered as a flexible energy, the authors optimize the reserve amount by cost-benefit analysis. The result is demonstrated by reliability test system (RTS 96), which confirms the proposed approach can work efficiently. [4] states that the large amount of wind power integration will not only impact the electricity market price, but also the system technical operation. In order to cope with the uncertainty of wind power operation, a more flexible power system is required to maintain the stability and reliability, which means more reserve is required in the system. The authors built a stochastic multi-stage linear model to study the correlation of the wind power integration and the electricity market price. The stochastic model is further studied in [30].

In [22], a novel reserve management tool (RMT) is used to compute how much reserve is needed in the daily market to support system operations. The Portuguese power system is used as a test bench to demonstrate the efficiency of the tool. For ensuring the voltage stability of the power system, [1] proposes a new method to develop the economical dispatch for power operators. The improved method works with very good performance because of the increased voltage stability margin during the insecure intervals.

In [35], a new model is presented to optimize the reserve market and can be used by Independent System Operators (ISO). The new security-constrained unit commitment model based on day-ahead algorithm can satisfy to the security constrain and minimize the power operating cost simultaneously and efficiently. In [31], the authors discuss the correlation of economic dispatch, frequency regulation control and unit commitment with high wind energy penetration.

The authors in [34] use the autoregressive moving average process model (ARMA) to simulate the average hourly wind speed. Compared with the regular persistence 
models, the result shows the wind speed forecasting is improved significantly. Five different locations are used as examples to demonstrate the improvement of the new proposed model.

In [20], the authors revise a dispatched method to meet the demand of achieving both low cost and low air pollution. The air pollution damage is formulated as a function of spatial distribution of pollutants. An interactive search method, which is devised in this paper, is used as auxiliary tool to aid the decision maker to get the optimal dispatch. Due to the benign environmental effects of the motivation [17], the wind power penetration continues to increase in the electricity market. The authors propose an efficient method to evaluate the system reliability based on Monte Carlo simulation. The paper present a 6-step wind speed model of multiple geography locations to simulate the result and the Canadian wind data is studied on the test system.

A methodology in [2], which aims to minimize the energy loss, is proposed to allocate different types of renewable generation units optimally. The most notable renewable energy in this paper is solar thermal systems, wind power, photovoltaic, biomass, and hydraulic power. A novel approach is applied in a distribution system with several available combinations of the renewable distributed generations units. The constraints include voltage limits, energy penetration limits, etc.

In [38], a chance-constrained two-stage (CCTS) program is formulated aiming to present a unit commitment method with wind power. A novel model is built to maintain the system reliability and respond to the wind forecasting errors. In the approach, chance constrain is used to describe different policies. Numerical examples are provided in the end to demonstrate the result. In [21], the author presents a load dispatch model is built include both wind turbines and thermal turbines.

A mixed-integer linear program is formulated for the unit commitment problem in [5], which aids to reduce the computational complexity. A similar linear program 
has been used commercially to solve the unit commitment problems in large scale in this paper.

In [28], a linear prediction methodology has been used for wind power forecasting. The results illustrate the usefulness and efficiency of the proposed linear model.

In [40], a analysis on economic dispatch (ED) for minimizing the power operating cost in electrical power system is proposed. An economic dispatch model is developed both on conventional generators and wind power generators. According to the characteristics of wind speed, the authors introduce the Weibull probability density function (pdf) for results of the proposed model. The optimization problem is computed by a combination which consists two conventional generators and two wind generators are applied to the ED model. Two parameters are used to describe the operating cost of the system. In our thesis, the reserve cost is also considered when the power demand is overestimated. The proposed method will be improved and more accurate if we consider the penalty cost for the wind energy in our thesis. Different methods are presented in [32] to calculate the parameters of Weibull wind speed distribution for wind power analysis, including the graphical method, the maximum likelihood method and the proposed modified maximum likelihood method. In general, Weibull distribution is used to ensure and evaluate the reliability of the system. According to the characteristics of Weibull distribution, the proposed system would achieve better performance.

A new economic dispatch algorithm is described in [24]. A compromise is achieved between the fuzzy constraints of wind power penetration and the generating cost variation. The proposed problem is formed as a Zadeh's classical symmetrical fuzzy programming. A Lagrangian function is built for the numerical results.

[37] describes a bi-objective economic dispatch method with considering different wind penetration. A novel algorithm called multi-objective particle swarm optimization is proposed to make a compromise economic scheduling between secu- 
rity requirements and economic dispatch. The fuzzy membership functions in this thesis aims to make the trade-off between risk and cost significantly increase the system stability.

In [27], many proposed approaches on economic dispatch with wind penetration are reviewed. Long term and short term economic dispatch models are built to schedule the hybrid power system. Different optimization algorithms in electricity market are discussed.

As stated above, many approaches have been established to optimize modern power systems with renewable energy. Most of the methods are evaluated for ensuring the trade-off between the system reliability and the unit price of the production power. Some proposed approaches do not pay much attention on the impacts of wind generation uncertainty, which will effect the system reliability, and the renewable energy is only considered to serve the spot market in these methods. In this thesis, a new approach aims to minimize the power operating cost based on genetic algorithm is proposed, which considers the use of the wind energy in both spot market and reserve market. The uncertainty of the wind energy is incorporated into the proposed approach to ensure the reliability of the system. 


\section{Chapter 3}

\section{Joint statistical scheduling of economic dispatch and energy}

\section{reserves}

In this chapter, the joint scheduling of economic dispatch and energy reserves is formulated as an optimization problem with power operating cost objective function and probabilistic constraints. The constrained genetic algorithm is used for solving the optimization problem for minimum power operating cost.

\subsection{Wind turbine modelling}

\subsubsection{Wind turbine characteristics}

The power-speed characteristics of a wind turbine is considered as important features. For a regular wind turbine, the power generation $P_{w}$ as a function of wind speed and wind turbine characteristics is given by [8]

$$
P_{w}=\frac{1}{2} C m v^{2}=\frac{1}{2} C(v S \rho)\left(v^{2}\right)=\frac{1}{2} C S \rho v^{3}=0.6 C S v^{3}
$$


where $\rho$ is the air density $\left(1.2928 \mathrm{~kg} / \mathrm{m}^{3}\right), S\left(\mathrm{~m}^{2}\right)$ is the swept area (cross-area) of the wind turbine, $v(\mathrm{~m} / \mathrm{s})$ is the wind velocity, and $C$ is the coefficient of the wind turbine, which depends on the ratio between the wind speed and the blade tip linear velocity. The power generation of a wind turbine generator can be computed according to (3.1.1).

\subsubsection{Statistical wind power generation modelling}

In this paper, the statistical wind power generation is modelled as following

- In our test bench system, the IEEE 24-bus Reliability Testing System (IEEERTS), 4 wind farms are used to substitute the 4 conventional power plant in the IEEE-RTS. The 4 wind farms with nominal generation capacity of 150 MW, $250 \mathrm{MW}, 400 \mathrm{MW}$ and $600 \mathrm{MW}$, respectively.

- Each wind farm consists of a number of wind turbines, each with installed capacity of $2 \mathrm{MW}$

- The wind speed data is acquired from NREL's Western Wind Resource Database. The wind speed information of each generator is chose randomly from database 5 times per day for 90 days.

- A sample of the output power of the wind farm with 400 MW nominal generation capacity is computed by (3.1.1). The output power results are fitted into Gaussian Distribution in Fig. 3.2. The output power of other wind farms are also studied in a similar way and fitted into Gaussian distributions.

Although the wind speed model has been simulated as Gaussian distribution for the primary researching, the wind speed distribution can be also proposed by more accurate algorithms, such as Rayleigh distribution and Weibull distribution, which are typically used to simulate the wind speed distribution. In statistics, the 
Weibull distribution is a continuous probability distribution which is widely used in reliability evaluating of systems.

\subsection{Formulation of Joint Economic Dispatch and En- ergy Reserves}

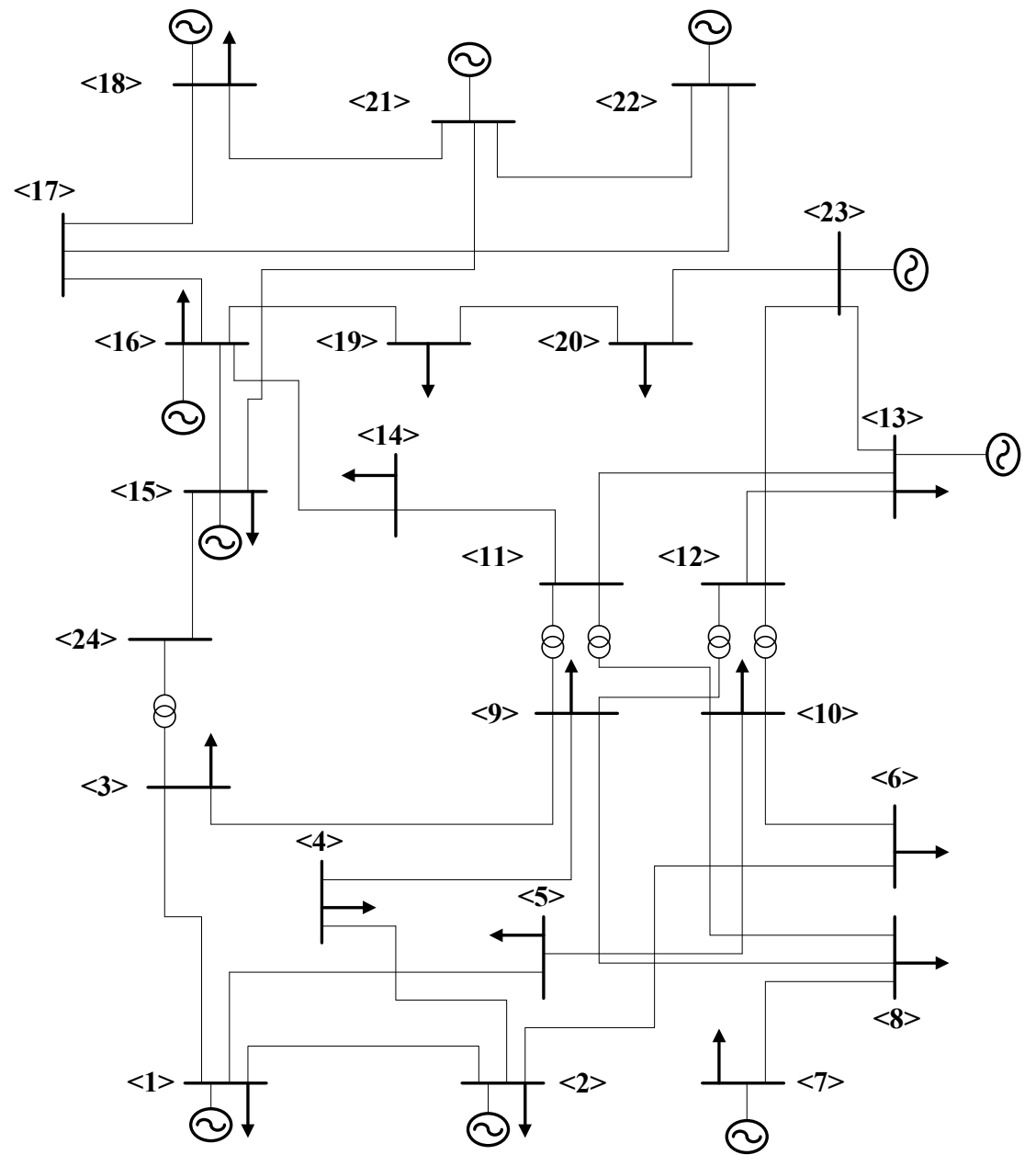

Figure 3.1: IEEE 24-bus RTS.

The joint economic dispatch and energy reserves is formulated as a optimization problem aiming to find the lowest power operating cost in a hybrid power system. 
As shown in Fig. 3.1, the IEEE 24-bus Reliability Testing System (IEEE-RTS) is used as the test bench for the study, which contains 10 generators, 24 buses, 5 transformers, 38 transmission lines and 17 loads. It is assumed that 6 generators in the power system are conventional energy generators and the rest are wind turbine generators. The optimization formulation including a objective function and constrains is described as the following.

$$
\underset{C_{i}, C_{W_{j}}, C_{R_{j}}, P_{G_{i}}, P_{W_{j}}, P_{R_{j}}}{\arg }\left\{\sum_{i=1}^{M} C_{i} P_{G_{i}}+\sum_{j=1}^{N} C_{W_{j}} P_{W_{j}}+\sum_{j=1}^{N} C_{R_{j}} P_{R_{j}}\right\}
$$

subject to $(3.2 .2),(3.2 .3),(3.2 .4),(3.2 .5),(3.2 .6)$.

$$
\begin{array}{r}
C_{\text {low }} \leqslant C_{i}, C_{W_{j}}, C_{R_{j}} \leqslant C_{\text {high }} \\
P_{\text {low }} \leqslant P_{G_{i}}, P_{W_{j}}, P_{R_{j}} \leqslant P_{\text {high }} \\
P_{G_{i}}+\left(P_{W_{j}}+P_{R_{j}}\right)=P_{\text {load }} \\
\sum_{i=1}^{M} P_{G_{i}} \leqslant P_{\text {load }} \times \gamma \\
P_{W_{j}}+P_{R_{j}} \leqslant P_{h i g h}\left(W_{j}\right)+P_{h i g h}\left(R_{j}\right) \\
\operatorname{Pr}\left\{\sum_{j=1}^{n}\left(P_{W_{j}} C_{W_{j}}+P_{R_{j}} C_{R_{j}}\right) \leqslant b\right\} \geqslant \alpha
\end{array}
$$

Here, the output power, which is supplied by the set of the conventional generators is defined as $P_{G}$. The deloaded wind turbine generators are used in this paper and the remaining power of the wind turbine generators are used for contingency reserve. $P_{W}$ and $P_{R}$ denote the power supplied in the spot market and the reserve market, respectively. The conventional generators' output power is denoted as $P_{G}=\left\{P_{G_{1}}, P_{G_{2}}, \cdots, P_{G_{M}}\right\}$, where $P_{G_{m}}$ denotes the output power of the $m$ th conventional generator. $P_{W}=\left\{P_{W_{1}}, \cdots, P_{W_{N}}\right\}$ is used to denote the output power of the wind turbine generators in spot market, where $P_{W_{n}}$ indicates the $n$th wind turbine generator output. The wind turbine generators' output power in reserve 
market is defined as $P_{R}=\left\{P_{R_{1}}, \cdots, P_{R_{N}}\right\}$, where $P_{R_{n}}$ denotes the power which can be supplied by the $n$th wind turbine generator in the reserve market. $C_{i}$ is the power operating cost of conventional generators in per unit. The power operating costs in per unit of wind turbine generators in spot market and reserve market are denoted as $C_{W_{j}}$ and $C_{R_{j}}$, respectively. $C_{\text {low }}$ and $C_{\text {high }}$ are used to denote the upper and lower price limit for the power operating cost in per unit, respectively. $P_{l o w}$ and $P_{h i g h}$ are used to indicate the upper and lower power output limit of each generator. The power demand is described as $P_{\text {load }} \cdot \gamma$ is used to define the ratio of the conventional power with respect to $P_{\text {load }}$. $P_{\text {high }}\left(W_{j}\right)+P_{\text {high }}\left(R_{j}\right)$ is the maximum output for the $j$ th wind turbine generator. It is noted that the actual output power of each wind turbine generator must be less than its maximum power generation. In (3.2.7), the total operating cost of generating $P_{W_{j}}+P_{R_{j}}$ wind power should be equal or less than $b$ with the probability that is larger than $\alpha$.

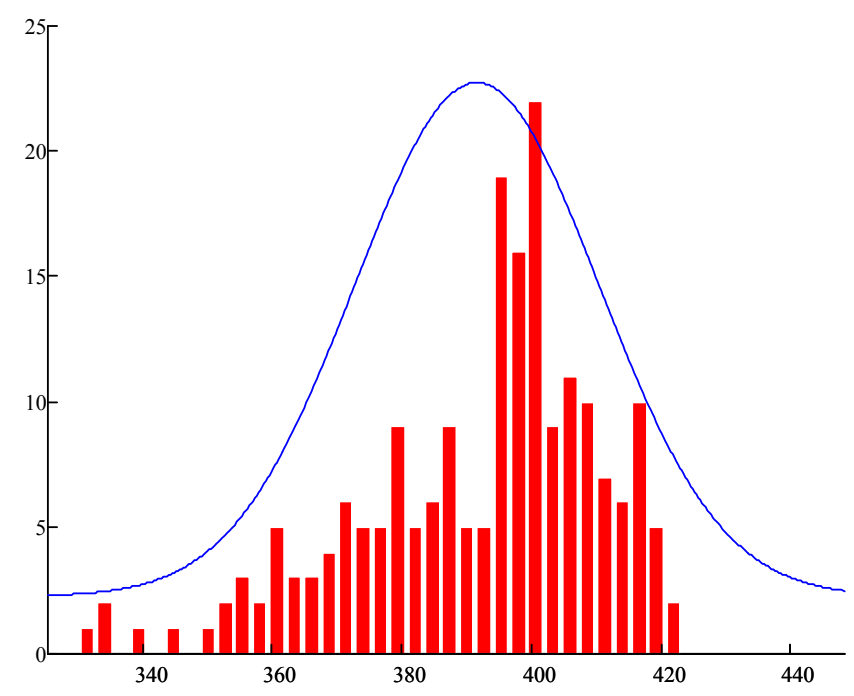

Figure 3.2: Gaussian distribution. 


\subsection{Derivation and transformation of chance constraint}

The "chance constraint" is used to describe that the probability of a random event should be larger than a threshold, which is given as

$$
\operatorname{Pr}\left\{\sum_{i=1}^{n} a_{i} x_{i} \leqslant b\right\} \geqslant \alpha
$$

where the event is denoted as $\sum_{i=1}^{n} a_{i} x_{i} \leqslant b$, and the probability of this random event is required at least equals to $\alpha$. Here, $a_{i}$ and $x_{i}$ are random variables, and $b$ and $\alpha$ are two variables that determines the constraints.

Accordingly, we define the following formulation for defining the chance constraint in our optimization problem as

$$
\operatorname{Pr}\left\{\sum_{j=1}^{n}\left(P_{W_{j}} C_{W_{j}}+P_{R_{j}} C_{R_{j}}\right) \leqslant b\right\} \geqslant \alpha .
$$

Although chance constraints have been used for solving other probabilistic constrained problems, the constraint in (3.3.2) cannot be directly used in solving the optimization as it does not provide the explicit relationship among $P_{W_{j}}, P_{C_{W_{j}}}, C_{W_{j}}$, $C_{R_{j}}, b$ and $\alpha$. As a result, the formula needs to be transformed into a mathematical form that can be directly used by computational algorithms, the transformation of the chance constraint is given as

$$
y\left(C_{W_{j}}, C_{W_{j}}\right)=\sum_{i=j}^{n}\left(P_{W_{j}} C_{W_{j}}+P_{R_{j}} C_{R_{j}}\right)-b .
$$

(3.3.3) also obeys the normal distribution, so the expectation (E) and variance (V) are:

$$
E\left(y\left(C_{W_{j}}, C_{W_{j}}\right)\right)=\sum_{j=1}^{n}\left\{E\left[P_{W_{j}}\right] C_{W_{j}}+E\left[P_{R_{j}}\right] C_{R_{j}}\right\}-E[b]
$$




$$
V\left(y\left(C_{W_{j}}, C_{W_{j}}\right)\right)=\sum_{j=1}^{n}\left\{V\left[P_{W_{j}}\right] C_{W_{j}}^{2}+V\left[P_{R_{j}}\right] C_{R_{j}}^{2}\right\}+V[b]
$$

From (3.3.4) and (3.3.5), we can derive,

$$
\frac{\sum_{i=1}^{n}\left(P_{W_{j}} C_{W_{j}}+P_{R_{j}} C_{R_{j}}\right)-b-\left\{\sum_{i=1}^{n}\left\{E\left[P_{W_{j}}\right] C_{W_{j}}+E\left[P_{R_{j}}\right] C_{R_{j}}\right\}-E[b]\right\}}{\sqrt{\sum_{i=1}^{n}\left\{V\left[P_{W_{j}}\right] C_{W_{j}}^{2}+V\left[P_{R_{j}}\right] C_{R_{j}}^{2}\right\}+V[b]}} \sim N(0,1)
$$

Furthermore, (3.3.1) is equivalent to the following,

$$
\begin{aligned}
& \frac{\sum_{i=1}^{n}\left(P_{W_{j}} C_{W_{j}}+P_{R_{j}} C_{R_{j}}\right)-b-\left\{\sum_{i=1}^{n}\left\{E\left[P_{W_{j}}\right] C_{W_{j}}+E\left[P_{R_{j}}\right] C_{R_{j}}\right\}-E[b]\right\}}{\sqrt{\sum_{i=1}^{n}\left\{V\left[P_{W_{j}}\right] C_{W_{j}}^{2}+V\left[P_{R_{j}}\right] C_{R_{j}}^{2}\right\}+V[b]}} \\
& \leqslant-\frac{\left\{\sum_{i=1}^{n}\left\{E\left[P_{W_{j}}\right] C_{W_{j}}+E\left[P_{R_{j}}\right] C_{R_{j}}\right\}-E[b]\right\}}{\sqrt{\sum_{i=1}^{n}\left\{V\left[P_{W_{j}}\right] C_{W_{j}}^{2}+V\left[P_{R_{j}}\right] C_{R_{j}}^{2}\right\}+V[b]}}
\end{aligned}
$$

According to (3.3.7), (3.3.1) can be deformed as follow. The summary of the formula transformation is described after that.

$$
\begin{gathered}
\operatorname{Pr}\left\{\frac{\sum_{i=1}^{n}\left(P_{W_{j}} C_{W_{j}}+P_{R_{j}} C_{R_{j}}\right)-b-\left\{\sum_{i=1}^{n}\left\{E\left[P_{W_{j}}\right] C_{W_{j}}+E\left[P_{R_{j}}\right] C_{R_{j}}\right\}-E[b]\right\}}{\sqrt{\sum_{i=1}^{n}\left\{V\left[P_{W_{j}}\right] C_{W_{j}}^{2}+V\left[P_{R_{j}}\right] C_{R_{j}}^{2}\right\}+V[b]}}\right. \\
\left.\leqslant-\frac{\left\{\sum_{i=1}^{n}\left\{E\left[P_{W_{j}}\right] C_{W_{j}}+E\left[P_{R_{j}}\right] C_{R_{j}}\right\}-E[b]\right\}}{\sqrt{\sum_{i=1}^{n}\left\{V\left[P_{W_{j}}\right] C_{W_{j}}^{2}+V\left[P_{R_{j}}\right] C_{R_{j}}^{2}\right\}+V[b]}}\right\} \geqslant \alpha .
\end{gathered}
$$




$$
\begin{aligned}
& \operatorname{Pr}\left\{\sum_{j=1}^{n}\left(P_{W_{j}} C_{W_{j}}+P_{R_{j}} C_{R_{j}}\right) \leqslant b\right\} \\
= & \operatorname{Pr}\left\{\sum_{j=1}^{n}\left(P_{W_{j}} C_{W_{j}}+P_{R_{j}} C_{R_{j}}\right)-b \leqslant 0\right\} \\
= & \operatorname{Pr}\left\{\frac{\sum_{i=1}^{n}\left(P_{W_{j}} C_{W_{j}}+P_{R_{j}} C_{R_{j}}\right)-b-\left\{\sum_{i=1}^{n}\left\{E\left[P_{W_{j}}\right] C_{W_{j}}+E\left[P_{R_{j}}\right] C_{R_{j}}\right\}-E[b]\right\}}{\sqrt{\sum_{i=1}^{n}\left\{V\left[P_{W_{j}}\right] C_{W_{j}}^{2}+V\left[P_{R_{j}}\right] C_{R_{j}}^{2}\right\}+V[b]}}\right. \\
& \left.\leqslant-\frac{\sum_{i=1}^{n}\left\{E\left[P_{W_{j}}\right] C_{W_{j}}+E\left[P_{R_{j}}\right] C_{R_{j}}\right\}-E[b]}{\sqrt{\sum_{i=1}^{n}\left\{V\left[P_{W_{j}}\right] C_{W_{j}}^{2}+V\left[P_{R_{j}}\right] C_{R_{j}}^{2}\right\}+V[b]}}\right\} \\
= & \Phi\left\{-\frac{\sum_{i=1}^{n}\left\{E\left[P_{W_{j}}\right] C_{W_{j}}+E\left[P_{R_{j}}\right] C_{R_{j}}\right\}-E[b]}{\sqrt{\sum_{i=1}^{n}\left\{V\left[P_{W_{j}}\right] C_{W_{j}}^{2}+V\left[P_{R_{j}}\right] C_{R_{j}}^{2}\right\}+V[b]}}\right\} .
\end{aligned}
$$

The $\phi$ function is a cumulative distribution function, which can be computed directly. Considering (3.3.9) and (3.3.1), the following is derived

$$
\Phi\left\{-\frac{\sum_{i=1}^{n}\left\{E\left[P_{W_{j}}\right] C_{W_{j}}+E\left[P_{R_{j}}\right] C_{R_{j}}\right\}-E[b]}{\sqrt{\sum_{i=1}^{n}\left\{V\left[P_{W_{j}}\right] C_{W_{j}}^{2}+V\left[P_{R_{j}}\right] C_{R_{j}}^{2}\right\}+V[b]}}\right\} \geqslant \alpha
$$

Two steps are used to transform (3.3.10) to computable criteria as below. First, obtaining inverse functions of the both sides of (3.3.10) as

$$
\left\{-\frac{\sum_{i=1}^{n}\left\{E\left[P_{W_{j}}\right] C_{W_{j}}+E\left[P_{R_{j}}\right] C_{R_{j}}\right\}-E[b]}{\sqrt{\sum_{i=1}^{n}\left\{V\left[P_{W_{j}}\right] C_{W_{j}}^{2}+V\left[P_{R_{j}}\right] C_{R_{j}}^{2}\right\}+V[b]}}\right\} \geqslant \Phi^{-1}(\alpha) .
$$

Second, deriving the following formulation

$$
\sum_{j=1}^{n}\left\{E\left[P_{W_{j}}\right] C_{W_{j}}+E\left[P_{R_{j}}\right] C_{R_{j}}\right\}+\phi^{-1}(\alpha) \sqrt{\sum_{j=1}^{n}\left\{V\left[P_{W_{j}}\right] C_{W_{j}}^{2}+V\left[P_{R_{j}}\right] C_{R_{j}}^{2}\right\}+V[b]} \leqslant E(b) .
$$

In this paper, the equivalent revised and computable optimization formulation is as following. 


$$
\underset{C, P}{\arg \min }\left\{\sum_{i=1}^{M} C_{i} P_{G_{i}}+\sum_{j=1}^{N} C_{W_{j}} P_{W_{j}}+\sum_{j=1}^{N} C_{R_{j}} P_{R_{j}}\right\}
$$

subject to $(3.3 .14),(3.3 .15),(3.3 .16),(3.3 .17),(3.3 .18)$ and (3.3.19).

$$
\begin{array}{r}
C_{\text {low }} \leqslant C_{i}, C_{W_{j}}, C_{R_{j}} \leqslant C_{\text {high }} \\
P_{\text {low }} \leqslant P_{G_{i}}, P_{W_{j}}, P_{R_{j}} \leqslant P_{\text {high }} \\
P_{G_{i}}+\left(P_{W_{j}}+P_{R_{j}}\right)=P_{\text {load }} \\
\sum_{i=1}^{M} P_{G_{i}} \leqslant P_{\text {load }} \times \gamma \\
P_{W_{j}}+P_{R_{j}} \leqslant P_{h i g h}\left(W_{j}\right)+P_{h i g h}\left(R_{j}\right)
\end{array}
$$

with the derived chance constraint as follow.

$$
\begin{gathered}
\sum_{j=1}^{n}\left\{E\left[P_{W_{j}}\right] C_{W_{j}}+E\left[P_{R_{j}}\right] C_{R_{j}}\right\}+ \\
\phi^{-1}(\alpha) \sqrt{\sum_{j=1}^{n}\left\{V\left[P_{W_{j}}\right] C_{W_{j}}^{2}+V\left[P_{R_{j}}\right] C_{R_{j}}^{2}\right\}+V[b]} \leqslant E(b)
\end{gathered}
$$

\subsection{Genetic algorithm}

The genetic algorithm (GA) is an artificial intelligence algorithm to simulate natural evolutionary processes, through retaining a population of candidate solutions to search for the optimal one. Some techniques are used to create candidate, which is inspired by crossover and selection.

Genetic algorithm is usually implemented as a computer simulation method, which denotes that, for an optimization problem, the abstract representation of a number of candidate solutions use this algorithm to evolve toward better solutions. The evolution starts with completely random individual populations. In each generation, the fitness of the all creatures from the current generation is evaluated, 
multiple individual(creatures) is randomly selected (based on their fitness) and generate new population through natural selection, the new generated population will repeat the same procedure to generate the next generation until satisfying the requirement of the system.

\subsubsection{Methodology of GA}

In genetic algorithm, a certain number of individuals will be generated randomly. The operator can also intervene the generating process to improve the quality of the initial population. Each individual is evaluated in the current generation and obtains a corresponding fitness value from the fitness function (the objective function is always regarded as the fitness function in a system). The individuals in the same generation is sequenced with the fitness value from high to low [14], [13].

The procedure of generating next population of solutions includes two steps, i.e., selection and reproduction, and reproduction also includes crossover and mutation.

Selection is based on the fitness value of each individual, but it does not mean the level of the fitness value is the only policy to select the solutions. A local optimal solution will be generated if we simply choose the high fitness individuals. The selection criteria of Genetic Algorithm is that the individuals with higher fitness value will be more likely chose than the low fitness individuals.

The second step is to generate the solutions of the next generation population through a combination of genetic operators of crossover and mutation. A pair of selected solutions (called "parent") is used to breed a new pair of solutions (called "children"). Firstly, the "parents" start to work on crossover with a crossover probability, which is generally between 0.6 and 1 . The probability reflects how much feasibility the two selected individuals generate their "children" by crossover. And then the new "parents" generate their new "children" by mutation. The general GA has a fixed mutation constant, also known as the mutation probability, which is usu- 
ally considered as 0.1 or less. It represents the probability of mutation-occurrence. A new solution is created by generating a "children", which typically shares many characteristics of its "parents". The new generated solutions in the new generation population are not the same as the previous generation. The overall fitness will be increased by the process of generating, since only the best solutions are selected to breed the nest generating population. This procedure will repeat for multiple times until reaching the termination conditions $[16,19,19]$.

In GA, the termination conditions are as follow.

- The generated generations has already reached the required iteration number.

- The computing process has exceeded the computing resource constraints.

- The individual's fitness has reached a plateau or the highest ranking that continued evolution will not generate better results.

- A solution has reached that satisfies minimum criteria.

- A combination of two or more stop criteria are met.

In GA, the important parameters are as follow.

- Population size, it is the amount of individuals in the generating population.

- Probability of performing crossover.

- Probability of mutation, which determines the local search capability of GA.

- Termination criteria, which controls the termination of generating process.

\subsubsection{Genetic algorithm application}

In this paper, the objective function is used as the fitness function to compute the fitness of each individual in the same generation. 28 unknown variable exists in this fitness function, which contains 14 variables for price per unit and 14 variables for output power. The constraints with the objective function are established to ensure the wind penetration of the system, and also to ensure the variables of the objective function varies in valid ranges. The chance constraint is used to evaluate the relationship between the price and the system balance. The fitness function 
with constraints is used to generate new generations in GA. The results denote the lowest power operating cost of the demand load for the customers.

In this problem, the population size is chosen as 500, which is enough to generate the new generation population with pinpoint accuracy. The probabilities of performing crossover and mutation are 0.8 and 0.08 , respectively. The initial value of the 28 variables are also defined, which aid the algorithm to find the optimized results more efficiently. The computing process will terminate if the derivation of the two successive results are less than 1 . The optimal results of this model by GA are described in Chapter 4.

\subsubsection{Other information}

The commonly used optimization toolboxes, CPLEX and CVX, are not able to solve the proposed optimization problem, as the optimization constraints contain complex functions $[23,7]$, i.e., the derived chance constraint is much more complex than the quadratic problem. Compared with CPLEX and CVX, GA provides a flexible and robust way to find the global optimum solution for the optimization problem with the chance constraints. In $[14,13]$, a parallel computation method is provided to reduce the computation load of GA. As a result, the GA is chosen to solve the proposed optimization problem with the chance constraint. 


\section{Chapter 4}

\section{Numerical results}

In this chapter, the numerical results of GA based optimization of the power operating cost are demonstrated. The proposed approach is applied to the IEEE 24-bus RTS, which contains wind turbine generators. All the unit price data for the system, including the conventional energy and the renewable energy are from [6]. Sufficient historic data for training this model are provided by the National Renewable Energy Laboratory (NREL). The load demand range is assumed between $600 \mathrm{MWh}$ to $2800 \mathrm{MWh}$, which is based on the rated power of each generator. In [39], the average worldwide wind penetration is around $17 \%$ in 2013 . It is assumed three levels in this paper for high wind energy penetration, $30 \%, 33.3 \%$ and $40 \%$.

The objective function contain 28 variables, 14 for price per unit, 6 for conventional generating output power, 4 for wind turbine generator output power in spot market and 4 for wind turbine generator output power in reserve market.

The effect of the uncertainty of the wind energy prediction on the power system operation will be studied on the IEEE 24-bus RTS model. Three case studies are conducted on this system. Case 1 investigates a typical dispatch and energy reserve scheduling scenario. In Case 2, results on the comparison of different wind penetration ratios are demonstrated. In Case 3, results are provided on three different $\alpha$ 's 
in the chance constraint of (3.3.1). In the end, Monte Carlo simulation is conducted and used to test the reliability of the system.

\subsection{Results on a typical energy scheduling scenario}

In the typical energy scheduling scenario, the renewable energy penetration ratio and the chance constraint probability of the hybrid system are chose as $30 \%$ and 0.95 , respectively.

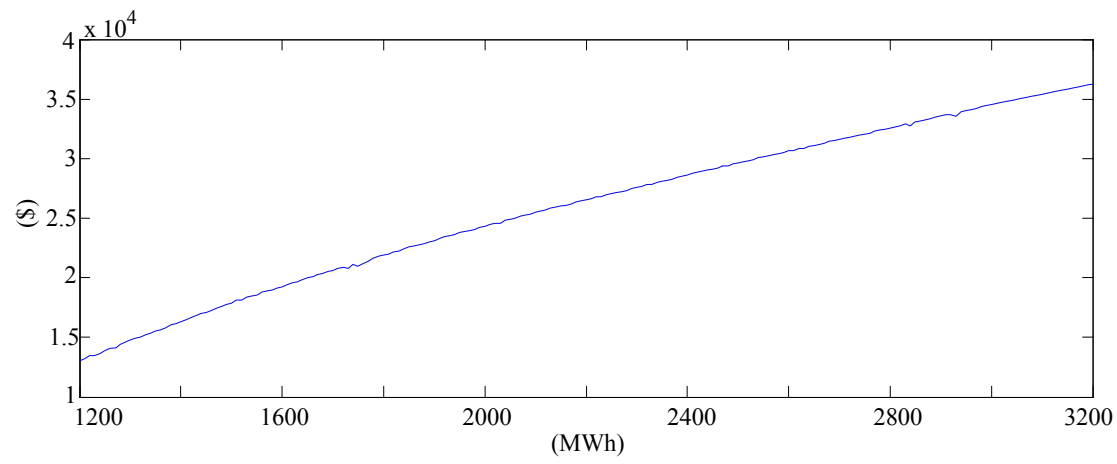

Figure 4.1: The total power operating cost of TG, WTG and RV.

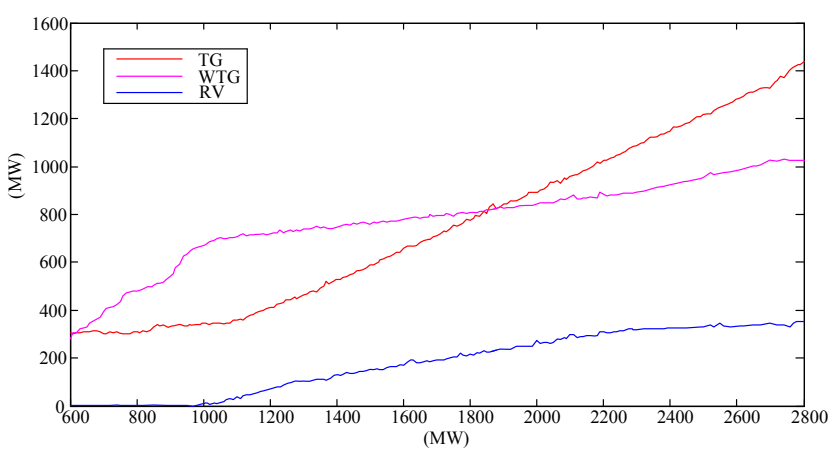

Figure 4.2: The total output power of TG, WTG and RV, respectively.

In Fig. 4.2, the optimized distribution of the total output power of the generators and reserves are illustrated as a function of the load demand ranging from $600 \mathrm{MW}$ to 2,800 MW. Before the total output power reach $1000 \mathrm{MW}$, the wind 


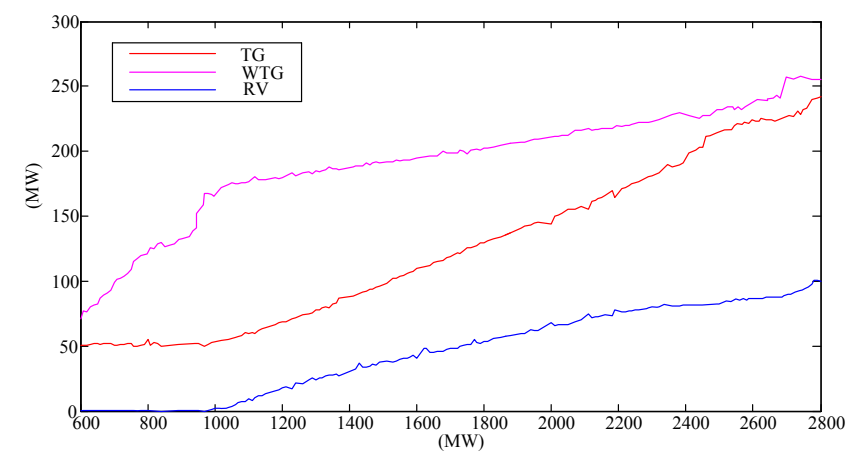

Figure 4.3: The average output power of TG, WTG and RV, respectively.

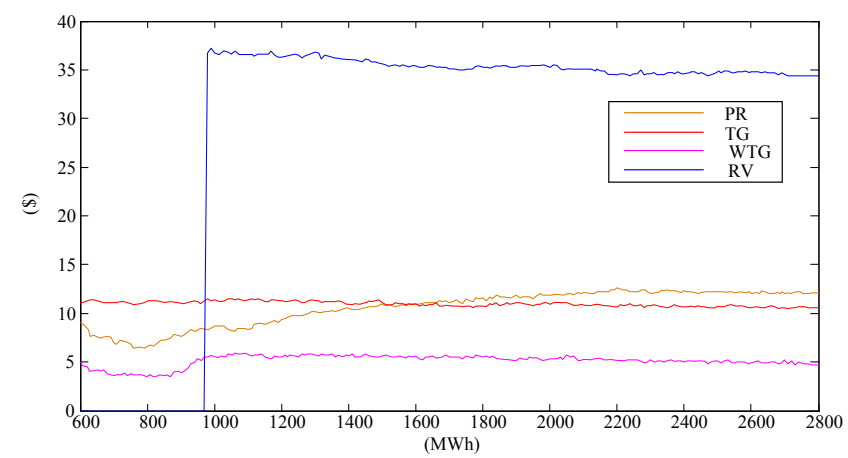

Figure 4.4: The average price of TG, WTG, RV and PR, respectively.

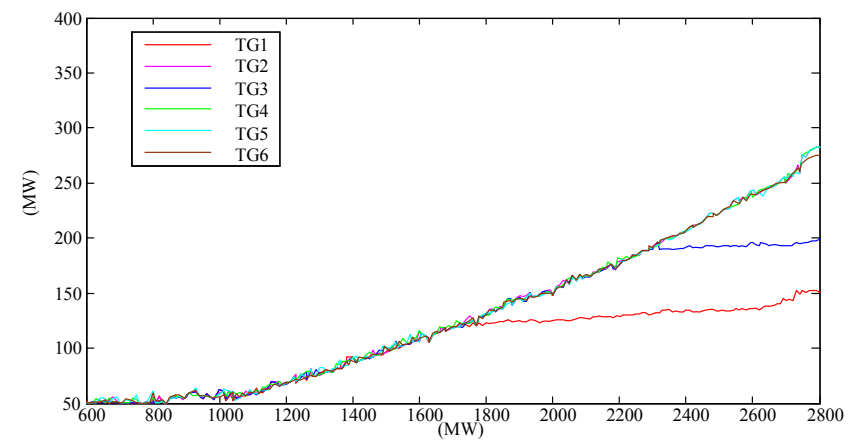

Figure 4.5: The output power of each TG, respectively.

power in spot market increases rapidly to its "stable value". According to the wind turbine characteristics in Gaussian distribution, we defined the value of the production power at the biggest probability as "stable value", which denotes the amount 


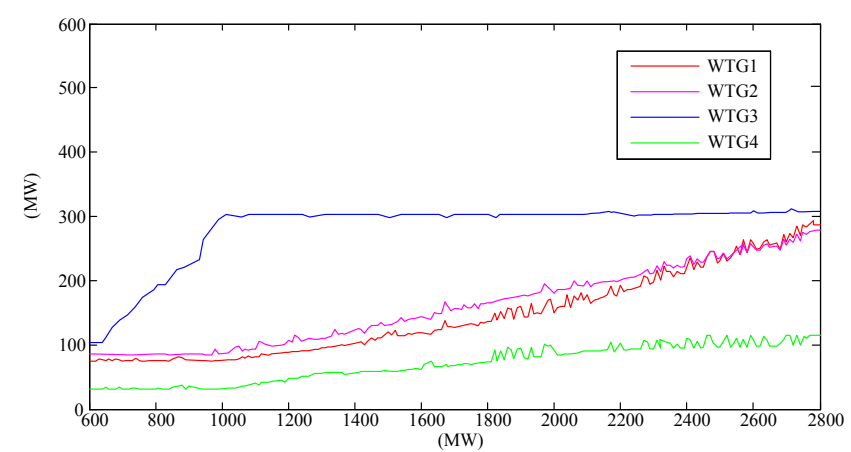

Figure 4.6: The output power of each WTG, respectively.

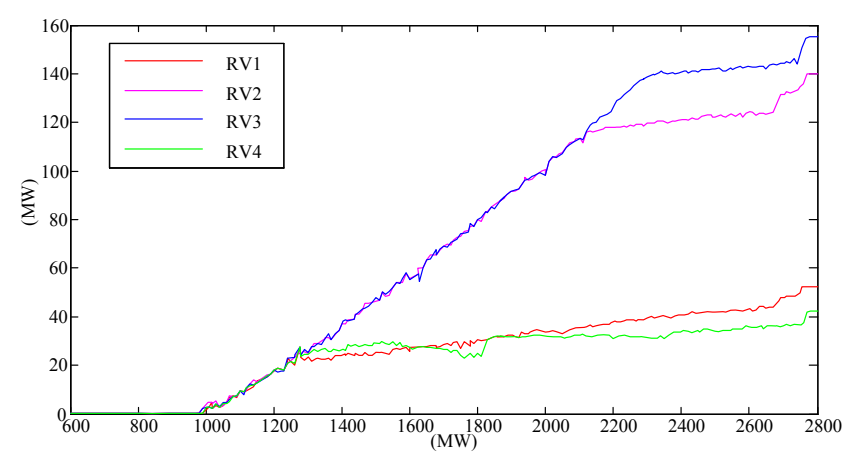

Figure 4.7: The output power of each RV, respectively.

of the production power of each generator is always around this point. The "stable value" for wind power in spot market and reserve market are fitted as $850 \mathrm{MW}$ and 350 MW, respectively, by their Gaussian distribution parameters. Meanwhile, the conventional power increase slightly. After the total power has reached $1000 \mathrm{MW}$, the increment speed of wind power in spot market starts to decrease, and the conventional generation increases rapidly. Because a fixed ramp rate is defined to the conventional generations output power, the wind power in reserve market starts to serve the system to satisfy the total load requirement. Considering the real-world applications, the ramp speed of the traditional generators is limited. The reserve power increases to its stable value slowly because the high price per unit does not contribute to minimization of the power operating cost. 
The growth trend of the conventional generators, renewable energy generators and energy reserves are demonstrated in Fig. 4.2. The average output power is illustrated in Fig. 4.3. Fig. 4.4 describes the average price for all the generated power, conventional power, wind power in spot market and reserve market. As we can see, the average price of reserve is the highest and the wind power in spot market keeps the lowest price, which meet the law of the present market. The average price in total is lower than the conventional power under $1000 \mathrm{MW}$, because the wind power in spot market is widely used during this period. After that, it starts to increase because the reserve power with high price is used.

The investigation on the total power generation is performed with increasing load demand in Fig. 4.1. In Fig. 4.5, Fig. 4.6 and Fig. 4.7, the detailed output power distribution of 6 conventional generators, 4 wind turbine generators for the spot market and 4 wind turbine generators for the reserve market are simulated respectively. From the three figures, all types of the power generation increase with load demand increasing and are within the constraints.

\subsection{Results on different wind energy penetrations ratios}

A comparison of the effects of different wind energy penetration ratios is demonstrated in this section. The numerical study scenarios include the total operating cost of the power generation for three different wind penetration ratios with increasing load demand. In Fig. 4.8, with chance constraint probability $\alpha=95 \%$, the three different colours denote the results corresponding to three different wind penetration ratios. As we can see, the system with wind energy penetration in $40 \%$ provides the minimal cost with the same amount of generated power. It can be seen from Fig. 4.8 that, a lower wind energy penetration ratio results in higher power operating costs. 


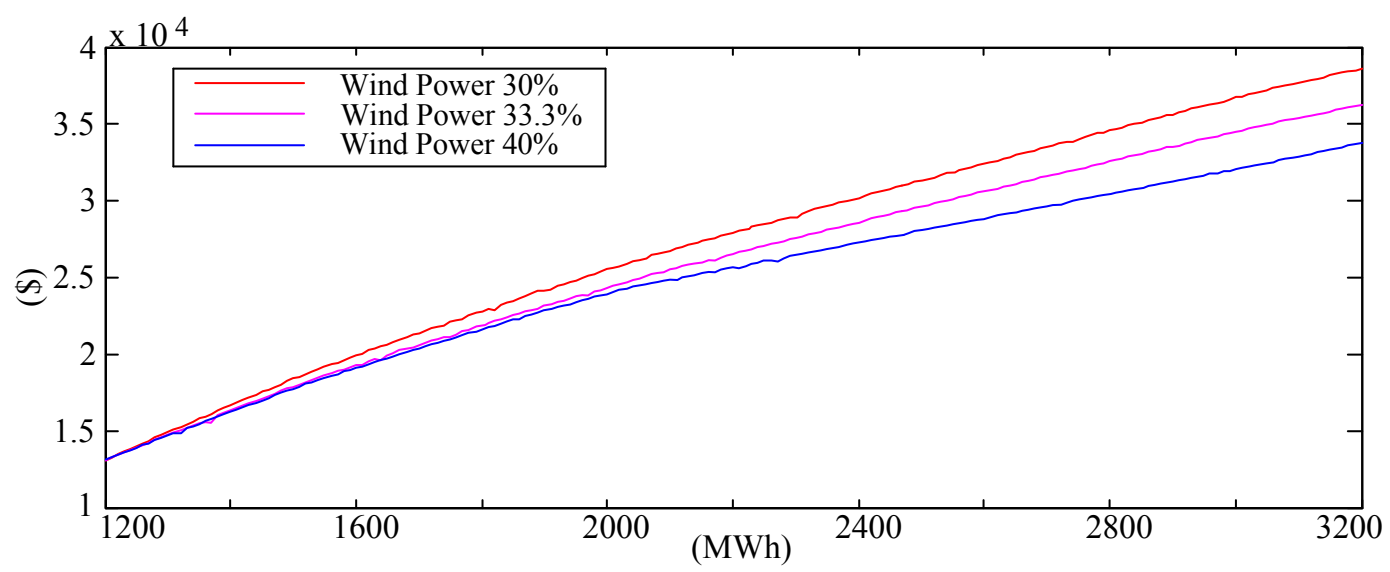

Figure 4.8: The total power operating costs of different wind energy penetrations.

\subsection{Results on different chance constraint probability}

In Case 3, the wind energy penetration ratio is fixed as $33.3 \%$, the chance constraint probability, $\alpha$ in (3.3.1), is defined as $90 \%, 95 \%$ and $99.73 \%$, respectively. As shown in Fig. 4.9, the operating costs corresponding to the three different probabilities increase gradually with increasing load demand. As we can see in Fig. 4.9 that the operating cost with the probability of $99.73 \%$ is lower than others. The highest cost is obtained with the probability of $90 \%$. This illustrates that the total power operating cost will change if the probability changes. In detail, the total cost increases with decreasing chance constraint probability. This is due to that a larger probability places a stricter constraint that the total cost of the renewable energy needs to be lower or equal to the demand price $b$ in (3.3.1). On the contrary, the operating cost increases if we define a smaller probability for the system, which means a weaker constraint is used for restricting the system. 


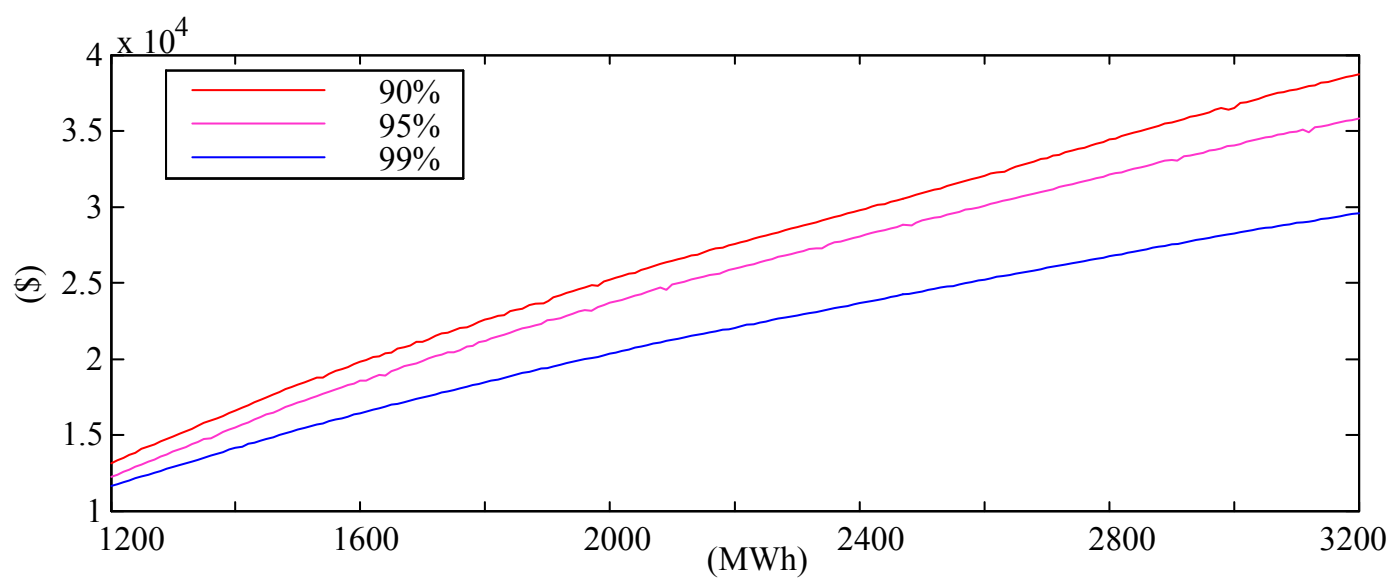

Figure 4.9: The total power operating cost with different chance constraints.

\subsection{The scheduling of economic dispatch and reserve energy on contingency problems}

In order to study the ability of the proposed approach in handling emergent events, the approach is tested on a system with sudden increment or reduction of the demand load. The detailed results are described in the following figures.

As an example, the emergency event is introduced in the simulation with duration of 10 minutes, as shown in Fig. 4.10. The start point of the system is $1000 \mathrm{MW}$ at the first minute. It is assumed that the demand load is suddenly increased from $1020 \mathrm{MW}$ to $1600 \mathrm{MW}$ at the 4 th minute.

After that, the load is reduced back to $1030 \mathrm{MW}$ at the 5th minute. The next significant increasing occurs at the 8th minute, when the demand load sharply increases from $1040 \mathrm{MW}$ at the 6th minute to $2400 \mathrm{MW}$ at the 8th minute, then the load reduces rapidly to $1050 \mathrm{MW}$ at the end of the 10 minute period. According to the described load change, the corresponding results are simulated, which demonstrates the efficiency of the proposed approach in this thesis. The figures below are used to described the results accurately which can be further researched. 


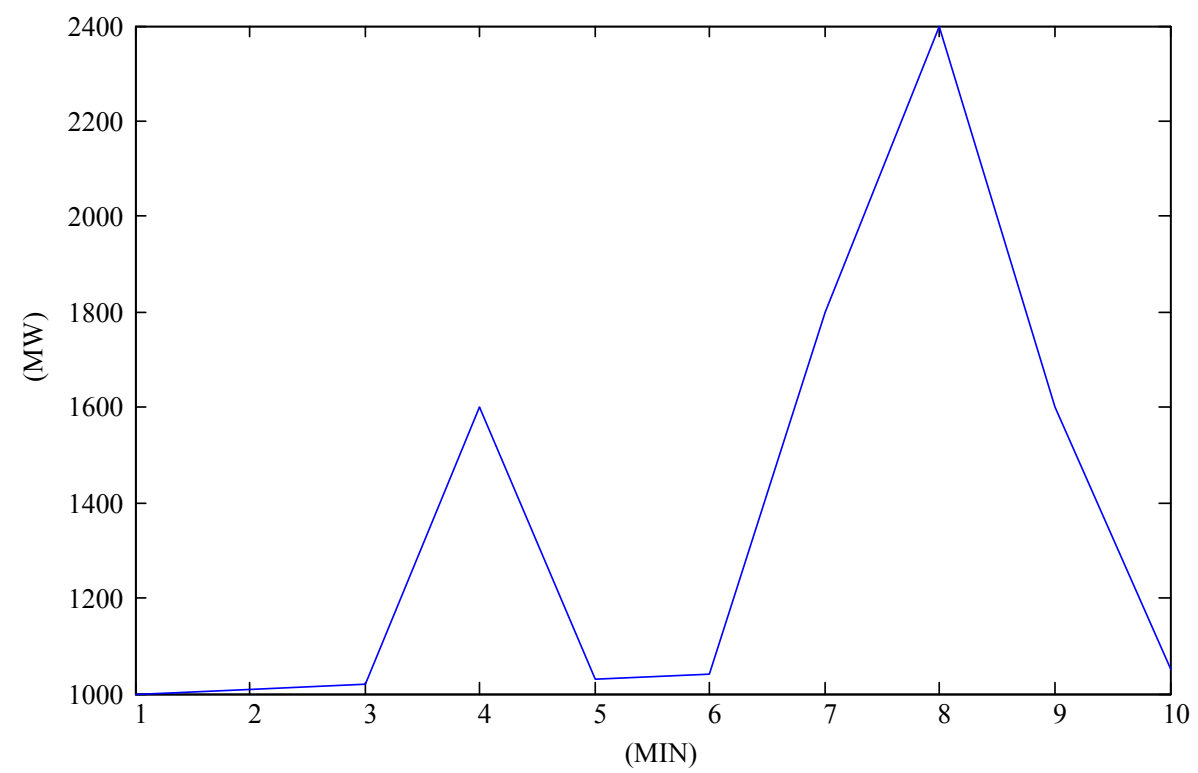

Figure 4.10: The emergency events of the system with sudden changes in load.

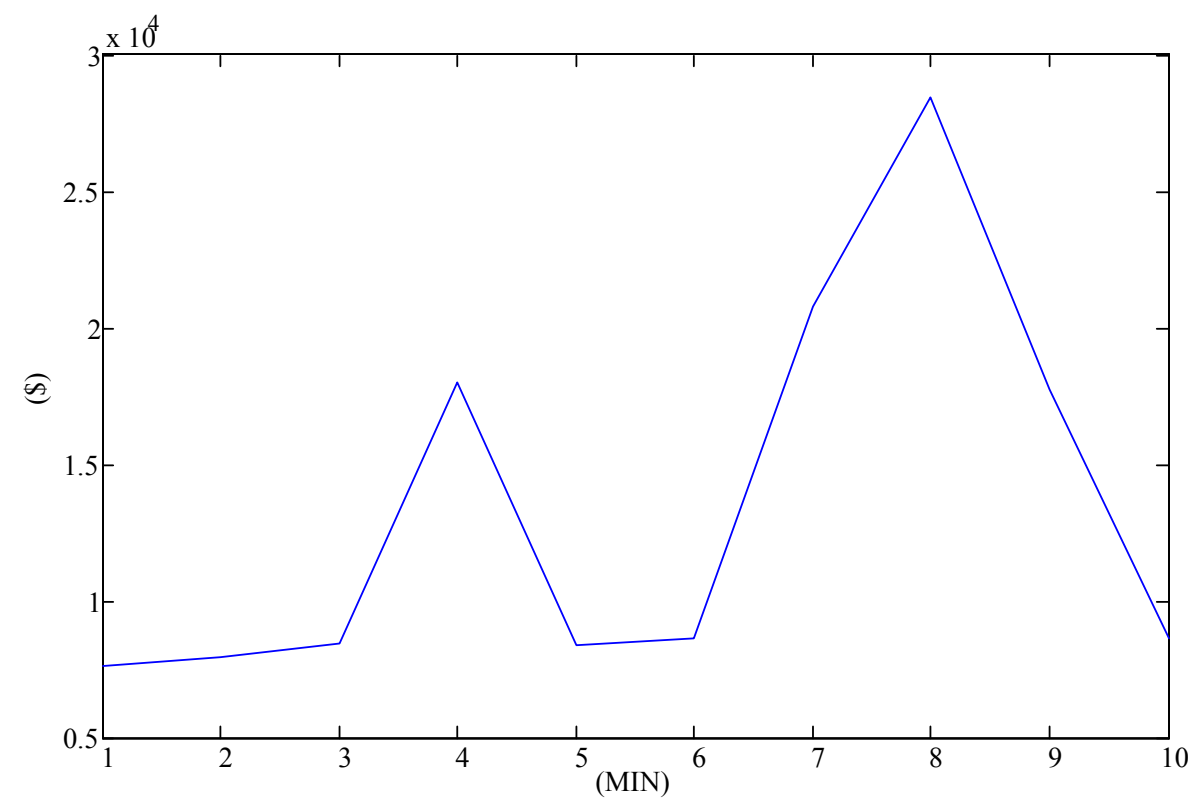

Figure 4.11: The total power operating cost at each minute.

In Fig. 4.11, the total power operating costs at each minute are illustrated. It is straightforward that the high demand load leads to high power generation cost. 


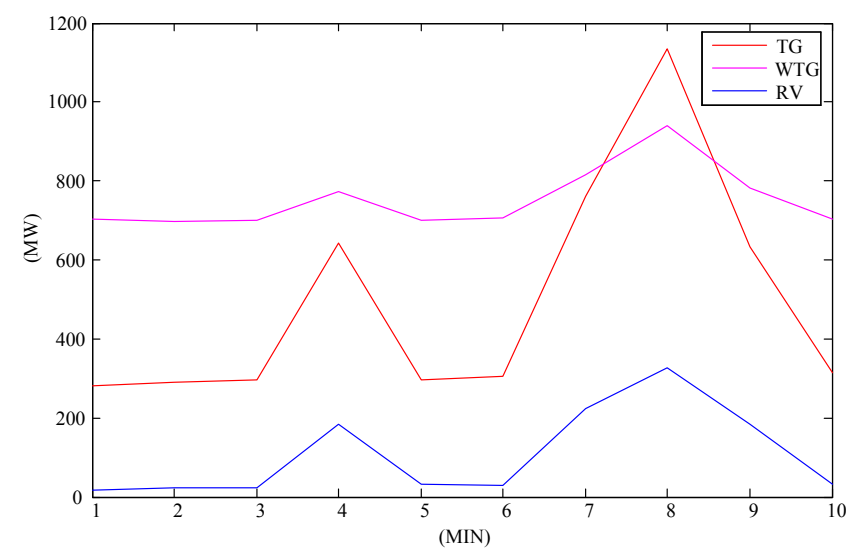

Figure 4.12: The total output power of TG, WTG and RV, respectively.

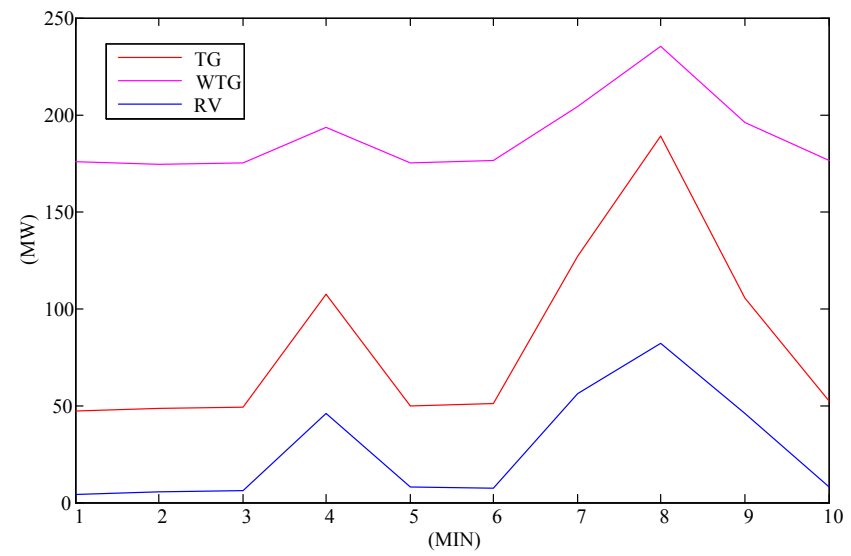

Figure 4.13: The average output power of TG, WTG and RV, respectively.

Fig. 4.12 describes the composition of the three kinds of power generation in the system. In the normal operation conditions, the wind power always supplies the biggest amount of the electricity in spot market because of its low price. According to the simulation results, the wind power in reserve market starts to serve the system when the demand load is over $1000 \mathrm{MW}$. At the 8th minute, the conventional generators produce the largest amount of power which exceeds the power production of wind turbine generators in spot market. It is due to that the amount of the power produced by wind turbine generators in the both spot market and reserve market 


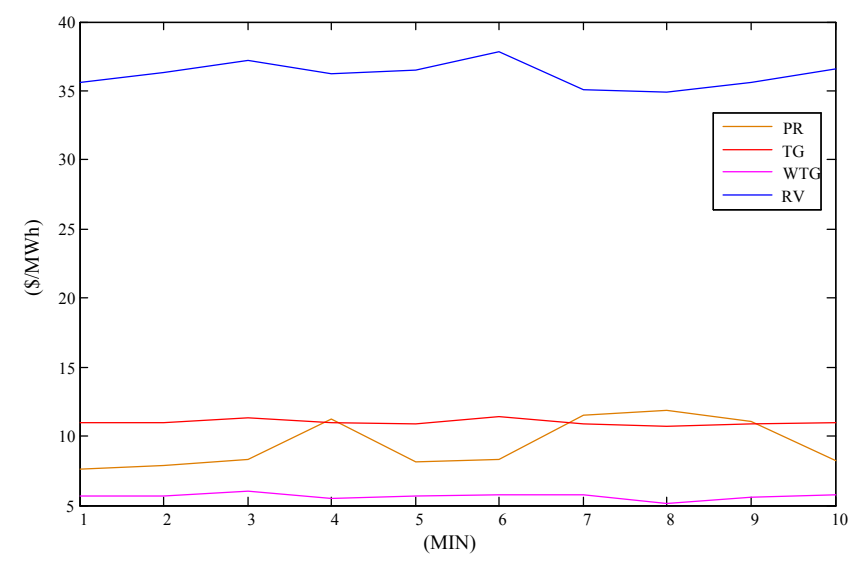

Figure 4.14: The average price of TG, WTG, RV and PR, respectively.

has almost reached the "stable values". The growth of the power production of the conventional generators increase rapidly at this time point. The average operating cost of each kind of generation on each generator is demonstrated in Fig. 4.13.

Fig. 4.14 shows the total average operating cost significantly increases at the 4 th minute and the 8th minute, because the reserve power is heavily used at these two time points. The average operating costs of the conventional generators and the wind turbine generators in the spot market maintain steady during the 10 minute period. The average operating cost of the reserve power reduces on the two time points because of its large amount of production.

Fig. 4.15, Fig. 4.16 and Fig. 4.17 explain the detailed power distribution for the 6 conventional generators and the 4 wind turbine generators (spot market and reserve market). The limits of the price and the power production decide how much power they will generate.

\subsection{Monte Carlo simulation}

In the numerical simulation, the Monte Carlo (MC) method is used to simulate the hybrid energy scheduling approach in Powerworld. The MC method is a compu- 


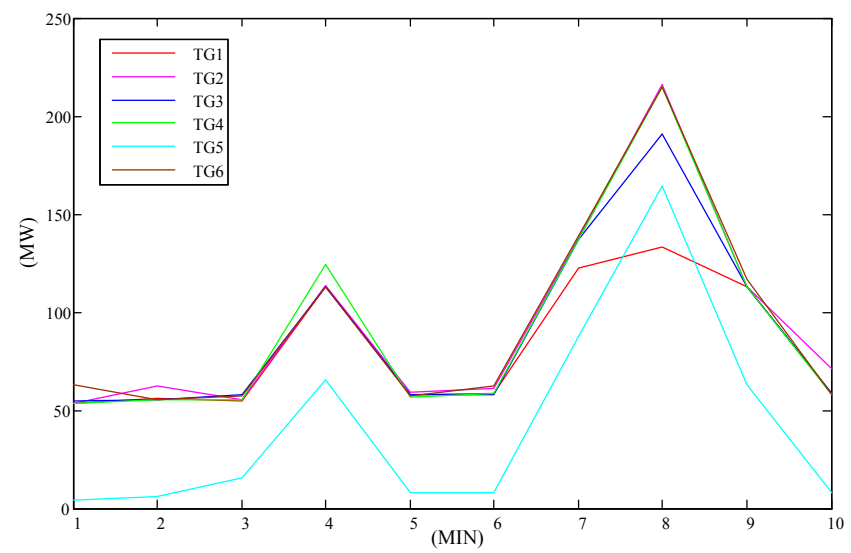

Figure 4.15: The output power of each TG, respectively.

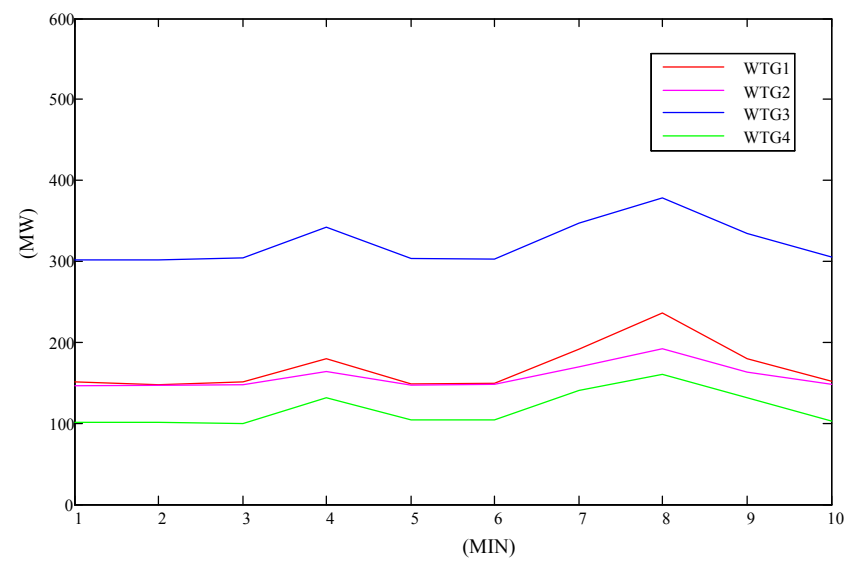

Figure 4.16: The output power of each WTG, respectively.

tational methodology that uses randomly sampled parameters to obtain numerical results of a stochastic system $[18,42]$. In this thesis, for each renewable energy penetration ratio, twenty sets of loads are chosen randomly to simulate the system price stability according to the optimum energy schedule results. For each chance constraints, twenty sets of loads are chosen randomly to simulate the system price stability in the same way. The MC simulation results demonstrate the feasibility and robustness of the proposed approach for the hybrid energy economy dispatch in the IEEE 24-bus RTS system which is shown in Fig. 4.18. 


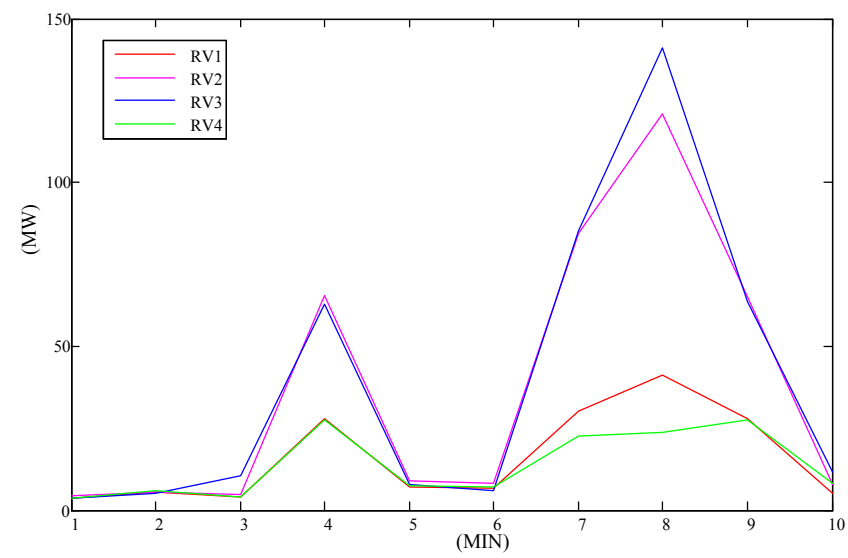

Figure 4.17: The output power of each RV, respectively.

Wind plants located on bus 15 and 16 are chosen randomly for generator outage simulation. Different wind speeds are simulated for the remaining wind plants in the system. The system is shown in the MC simulations to be stable in these scenarios and the results demonstrate the robustness of the propose approach. 


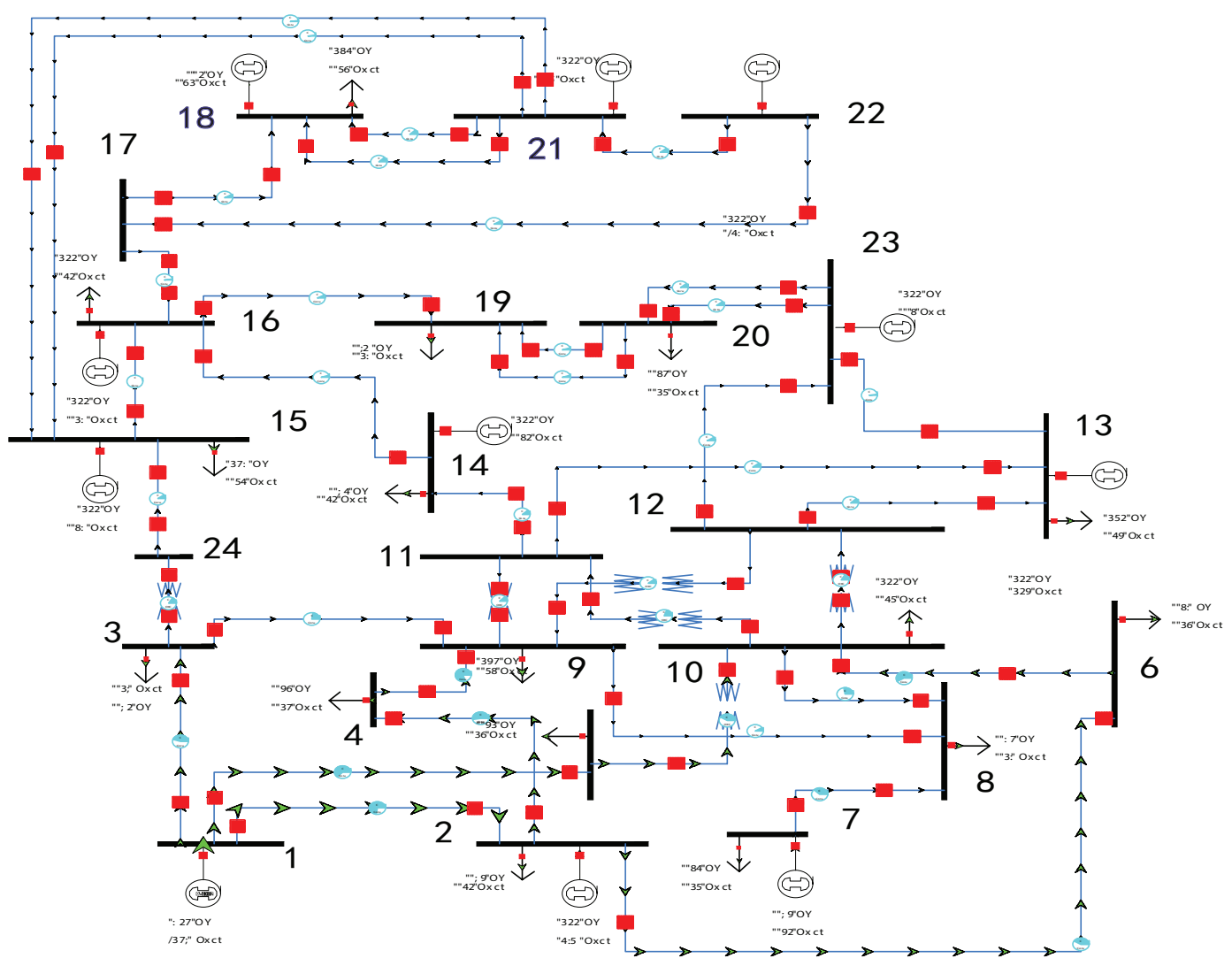

Figure 4.18: The Monte Carlo simulation test bench in Power World. 


\section{Chapter 5}

\section{Conclusion and future work}

\subsection{Conclusion}

In this paper, a stochastic approach in joint scheduling economic dispatch and energy reserves of hybrid power systems with high renewable energy penetration in electricity market has been presented. The motivation of the research work is the emerging issue in scheduling the economic dispatch and energy reserves of hybrid power system with high wind energy penetrations. A joint economic dispatch and energy reserve scheduling model in a hybrid power system with both conventional generators and wind turbine generators is proposed in the form of an optimization objective function and its associated constraint functions. The objective function of the proposed stochastic model is formulated to minimize the power operating cost. The chance constraint is used to formulate the statistical constraints of the system. Moreover, genetic algorithm is chosen to solve the optimization problem and compared with other popular algorithm. Our validated optimization results of the proposed model demonstrate its usefulness and efficiency, which is based on minimizing the power operating cost with constraints on power system reliability. The detailed numerical results are achieved from the IEEE 24-but RTS simulation 
test bench, and are discussed in the thesis. The applicability of the proposed statistical model and approach are tested and evaluated on the IEEE 24-bus RTS. In the numerical experiments, the total power operating costs are studied assuming the different probabilities in (3.3.1) for that the operating cost is lower than a preset threshold. Numerical experiments with three different thresholds in (3.3.1) is used for comparing the results. Fig. 4.9 demonstrates that our assumption, which relates to the probability of power operating cost, is valid and useful, which can be further investigated into a large range of applicable energy marketing scenarios. The Monte Carlo simulation approach is used to simulate the random output power of the generating units in this system. Using the proposed model, statistical power dispatch scheduling of conventional generators, renewable generators, and the optimized power operating cost of the hybrid power system are simultaneously determined.

\subsection{Future work}

In the future work, we will develop the following topics in details:

\subsubsection{Improvement of stochastic model with wind power}

- Optimizing the total power cost for on emergency event, such as natural and man-made hazards.

- For real-world applications, various types of wind turbine generators should be considered to establish accuracy correlative function between wind speed and electrical power.

- IEEE 24-bus RTS is used in this paper to simulate and detect the results of the proposed model, more complex models will be chosen to validate the proposed approach in a large-scale power system. 


\subsubsection{Improvement of the proposed method}

- The genetic algorithm is used in this paper to optimize the total operating cost of the hybrid power system. More efficient optimization algorithm will be employed to reduce the computational complexity.

- As [11], a practical method can be established to solve the optimal power flow problem with several variables, which aims to provide constraints on power flow.

- The reliability problems will emerge while the system become more complex, and the corresponding solution needs to be considered to ensure the system secure.

- In addition to the optimization of the power operating cost and the benefit for power suppliers, other objective functions will also be formulated based on the proposed method, such as maximizing the system reliability, minimizing the cumulative effect on environment, etc. 


\section{Bibliography}

[1] C. M. Affonso, L. Silva, F. Lima, and S. Soares. MW and MVAR management on supply and demand side for meeting voltage stability margin criteria. IEEE transaction on power systems, 19:1538-1545, 2004.

[2] Y. M. Atwa, E. F. Elsaadany, M. Salama, and R. Seethapathy. Optimal renewable resources mix for distribution system energy loss minimization. IEEE transaction on power systems, 25:360-370, 2010.

[3] K. Bae and J. S. Thorp. An importance sampling application: 179 bus WSCC system under voltage based hidden failures and relay misoperation. Proceeding of the Thirty-First Hawaii International Conference on System Sciences, 3:3946, 1998.

[4] R. Barth, H. Brand, P. Meibom, and C. Weber. A stochastic unit-commitment model for the evaluation of the impacts of integration of large amounts of intermittent wind power. In Probabilistic Methods Applied to Power Systems, 2006.

[5] M. Carrin and J. M. Arroyo. A computationally efficient mixed-integer linear formulation for the thermal unit commitment problem. IEEE transaction on power systems, 21:1371-1378, 2006. 
[6] R. Christie. Power system test archive. http://www.ee.washington.edu/research/pstca., 1999.

[7] IBM ILOG CPLEX. V12. 1: Users manual for cplex. International Business Machines Corporation, 46:157, 2009.

[8] R. Datta and V. T. Ranganathan. Variable-speed wind power generation using doubly fed wound rotor induction machinea comparison with alternative schemes. IEEE transactions on energy conversion, 17:414-421, 2002.

[9] E. A. DeMeo, W. Grant, M. R. Milligan, and M. J. Schuerger. Wind plant integration. IEEE Power \& Energy Magazine, 05:38-46, 2005.

[10] Y. Ding and P. Wang. Reliability and price risk assessment of a restructured power system with hybrid market structure. IEEE transaction on power systems, 21:108-116, 2006.

[11] H. W. Dommel and W. F. Tinney. Optimal power flow solutions. IEEE transaction on power apparatus and systems, PAS-87:1866-1876, 1968.

[12] H.B. Gooil, D.P. Mendes, K.R.W. Bell, and D.S. Kirschen. Optimal scheduling of spinning reserve. IEEE Transactions on Power Systems, 14:1485-1492, 1999.

[13] H. Heinz. Parallel genetic algorithms, population genetics and combinatorial optimization. Parallelism, Learning, Evolution, pages 398-406, 1991.

[14] H. Heinz, M. Schomisch, and B. Joachim. The parallel genetic algorithm as function optimizer. Parallel computing, 17:619-632, 1991.

[15] D. Ibrahim. Renewable energy and sustainable development: a crucial review. Renewable and Sustainable Energy Reviews, 4:157-175, 2000. 
[16] D. Kalyanmoy, P. Amrit, A. Sameer, and M. Tamt. A fast and elitist multiobjective genetic algorithm: Nsga-ii. Evolutionary Computation, IEEE Transactions on, 6:182-197, 2002.

[17] R. Karki, P. Hu, and R. Billinton. A simplified wind power generation model for reliability evaluation. IEEE transactions on energy conversion, 21:533-540, 2006.

[18] B. Kurt and H. Dieter. Monte Carlo simulation in statistical physics: an introduction. Springer, 2010.

[19] D. Lawrence et al. Handbook of genetic algorithms. Van Nostrand Reinhold New York, 1991.

[20] Z. Jacoband E. Lawrence. Economic-enviromental power dispatch. IEEE transaction on system, man and cybernetics, SMC-5:485-489, 1975.

[21] X. Liu. Economic load dispatch constrained by wind power availability: A wait-and-see approach. IEEE transaction on smart grid, 1:347-355, 2010.

[22] M. A. Matos and R. J. Bessa. Setting the operating reserve using probabilistic wind power forecasts. IEEE transaction on power systems, 26:594-603, 2011.

[23] G. Michael, B. Stephen, and Y. Ye. Cvx: Matlab software for disciplined convex programming, version 2.0 beta. Recent Advances in Learning and Control, pages 95-110, 2012.

[24] V. Miranda and P. S. Hang. Economic dispatch model with fuzzy wind constraints and attitudes of dispatchers. IEEE transaction on power systems, $20: 2143-2145,2005$. 
[25] M. Ortega-Vazquez and D. Kirschen. Estimating the spinning reserve requirements in systems with significant wind power generation penetration. IEEE Transactions on Power Systems, 24:114-123, 2009.

[26] M. A. Ortega-Vazquez and D. S. Kirschen. Estimating the spinning reserve requirements in systems with signi?cant wind power generation penetration. IEEE Transactions on Power Systems, 24:114-124, 2009.

[27] B. Ren and C. Jiang. A review on the economic dispatch and risk management considering wind power in the power market. Renewable and Sustainable Energy Reviews, 13:2169-2174, 2009.

[28] G.H. Riahy and M. Abedi. Short term wind speed forecasting for wind turbine applications using linear prediction method. Renewable Energy, 33:35-41, 2008.

[29] P. Rio and M. Burguillo. Assessing the impact of renewable energy deployment on local sustainability: Towards a theoretical framework. Renewable and Sustainable Energy Reviews, 12:1325-1344, 2008.

[30] P. A. Ruiz, C. R. Philbrick, E. Zak, K. W. Cheung, and P. W. Sauer. Uncertainty management in the unit commitment problem. IEEE Transactions on Power Systems, 24:642-651, 2009.

[31] R. A. Schlueter., G. L. Park., M. Lotfalian., H. Shayanfar., and J. Dorsey. Modification of power system operation for significant wind generation penetration. IEEE Transactions on Power Apparatus and Systems, PAS-102:153-161, 1983.

[32] J. V. Seguro and T.W. Lambert. Modern estimation of the parameters of the weibull wind speed distribution for wind energy analysis. Journal of Wind Engineering and Industrial Aerodynamics, 85:75-84, 2000.

[33] J. Teyssen and M. Fuchs. Wind report 2005. Technical report, E.ON Energie AG, 2005. 
[34] J. L. Torres, A. Garc, M. D. Blas, and A. D. Francisco. Forecast of hourly average wind speed with arma models in navarre (spain). Solar Energy, 79:65$77,2005$.

[35] J. Wang, M. Shahidehpour, and Z. Li. Contingency-constrained reserve requirements in joint energy and ancillary services auction. IEEE transaction on power system, 24:1457-1468, 2009.

[36] J. Wang, X. Wang, and Y. Wu. Operating reserve model in the power market. IEEE Transactions on Power Systems, 20:223-229, 2005.

[37] L. Wang and C. Singh. Balancing risk and cost in fuzzy economic dispatch including wind power penetration based on particle swarm optimization. Electric Power Systems Research, 78:1361-1368, 2008.

[38] Q. Wang, Y. Guan, and J. Wang. A chance-constrained two-stage stochastic program for unit commitment with uncertain wind power output. IEEE transaction on power system, 27:206-215, 2012.

[39] R. Wiser and M. Bolinger. 2011 wind technologies market report. Technical report, Lawrence Berkeley National Laboratory, 2011.

[40] A. J. Wood and B. F. Wollenberg. Power Generation, Operation, and Control. New York: Wiley, 1996.

[41] T. Yong, R. Entriken, and P. Zhang. Reserve determination for system with large wind generation. IEEE Power $\mathcal{E}$ Energy Society General Meeting, pages $1-7,2009$.

[42] Athanassios. Z. Direct determination of phase coexistence properties of fluids by monte carlo simulation in a new ensemble. Molecular Physics, 61:813-826, 1987. 